\title{
High performance work practices in small firms: a resource-poverty and strategic decision-making perspective
}

\author{
Brigitte Kroon · Karina Van De Voorde • \\ Jules Timmers
}

Accepted: 13 February 2012/Published online: 15 March 2012

(C) The Author(s) 2012. This article is published with open access at Springerlink.com

\begin{abstract}
High performance work practices (HPWPs) are human resource management practices aimed at stimulating employee and organisational performance. The application of HPWPs is not widespread in small organisations. We examine whether the implementation of coherent bundles of HPWPs (aimed at employee ability, employee motivation or at the opportunity to perform) depends on the scarcity of resources, as reflected in the size of the company, and on strategic decision-making in small firms related to the owner's expertise and attitudes. In our research, a total of 211 employees from 45 small organisations were asked to rate the presence of HPWPs in their organisation. These averaged perceptions were linked to information provided by the owner-managers on the size of their firm and their own expertise and attitudes. The findings support that smaller but coherent bundles of HPWPs can be found in small organisations and that
\end{abstract}

B. Kroon $(\bowtie) \cdot$ K. Van De Voorde · J. Timmers

Department of Human Resource Studies,

Tilburg University, PO Box 90153,

5000 LE Tilburg, The Netherlands

e-mail: B.Kroon@uvt.nl

J. Timmers

e-mail: j.h.timmers@gmail.com

K. Van De Voorde

Behavioural Science Institute, Radboud University, PO Box 9104, 6500 HE Nijmegen, The Netherlands

e-mail: k.vandevoorde@psych.ru.nl the implementation of these bundles depends on available resources, strategic decision-making and the combination of the two. These findings highlight the need to integrate the notions of resource poverty and strategic decision-making to understand the uptake of bundles of HPWPs within small firms.

Keywords High performance work system · Entrepreneurial orientation - Small firms $\cdot$ Human resource management $\cdot$ Resource poverty $\cdot$ Strategic decision making - Best-practice awareness . Innovative HR vision

JEL Classifications D22 - D89 - L26 - M12 - M51 · M52 - M53

\section{Introduction}

Research into human resource management (HRM) and performance in small firms has embraced the investigation of the presence of high performance work practices (HPWPs). HPWPs are modern employee management practices, such as formal employee training, high pay levels, group-based performance pay and self-directed teams (Appelbaum et al. 2000). It is claimed that increased implementation of HPWPs results in better performing organisations in terms of financial and employee outcomes (Combs et al. 2006). However, the uptake of the 
package of HPWPs has been found to be quite low in small firms (Kauhanen 2009; Way 2002). One of the unresolved issues is whether this low uptake is the result of smaller firms simply doing a bit of everything but in a less sophisticated manner than larger firms (Dandridge 1979; Mayson and Barrett 2006), or that smaller firms deliberately adopt smaller sets of related practices instead of the whole package of HPWPs. This avenue has not been explored much to date.

In order to understand this issue in greater depth, we turn to the theoretical foundation of HPWPs. Appelbaum et al. (2000) argued that a combination of three bundles of HR practices is theoretically involved in building a HPWP system (HPWPS). These bundles are: employee ability-enhancing practices (such as training and skill development) (A), employee motivation-enhancing practices (including high pay, career development and top-down information sharing) (M) and practices that give employees the opportunity to go the extra mile (such as employee involvement and teamwork) (O). Together, these are referred to as the AMO model of HPWPs. Although no distinction is made between these elements in most research, Boxall and Macky (2009) have recently theorised that each component of the AMO bundle is aimed at different goals, which in turn suggests that it may be possible to find organisations where only Ability or Motivation or Opportunity practices dominate (Toh et al. 2008). This concept of focussed bundles of HPWP could advance the debate on HRM and performance in small firms.

In the remainder of this paper we focus on two theoretical perspectives on the uptake of bundles of HPWS in small firms. First, we examine the straightforward assumption that the average uptake of ability and motivation practices is less in smaller organisations than in larger firms. The logic for this assumption lies in the notion of resource poverty (Welsh and White 1981). Compared to larger firms, small firms are more constrained by limited resources. In terms of financial resources, the low uptake of HPWPs in small firms has been related to the high costs involved in implementing all of the practices (Sels et al. 2006). In addition, the simple structure of smaller organisations allows for quick and relatively informal communication styles, which may conflict with the greater formality and relatively more time-consuming nature of the HPWP approach (Jack et al. 2006).

The second and more profound theoretical perspective holds that small firm owners, for various strategic considerations, adopt smaller but coherent bundles of HPWPs. Here we turn to the notion of strategic choice and the effect of the human capital of the owner on strategic decision-making in small firms (Child 1997). Given that most small firms do not employ a specialist HR professional, decision-making concerning HRM normally rests in the hands of the entrepreneur (Matlay 1999). Therefore, whether HPWPs are adopted depends on the beliefs of the entrepreneur with respect to the benefits of HRMrelated interventions as a solution for business issues (Cassell et al. 2002). This is illustrated by the finding that small firm owners consistently report that HR practices need to 'fit' their firm's conditions and needs (Drummond and Stone 2007; Harney and Dundon 2006). To further investigate this aspect, this paper builds on the decision-making models proposed by Cassell et al. (2002) and de Kok and Uhlaner (2001) which hold that the decision by a small firm's management to translate a company issue into an HR intervention depends on both the owner-manager's ability to make sense of the issue at stake and his/her strategic choice to apply the available resources (time and money). In particular, we examine the impact of the entrepreneurial orientation, HR vision and HPWP awareness of the firm owner on the extent to which each of the three separate AMO bundles are implemented in their firm.

By integrating these two theoretical perspectives on the uptake of HPWS bundles in small firms, namely, the resource-poverty and the strategic decisionmaking perspective, our aim is to advance the debate on the use and suitability of the HPWP model in smaller firms.

This study adds to the existing knowledge on HRM in small firms in three ways. First, previous research has mostly ignored the distinct performance goals of the three bundles and instead examined the impact of a single, all-encompassing HPWP system. Our intermediate approach, which focusses on smaller bundles, could advance our understanding of the presence of modern employee management practices in small firms. Second, we argue that strategic choice and the availability of resources differ considerably even within a population of micro- and small firms, thereby helping to explain potential variation in the uptake of HPWP bundles in such firm and helping to account for the reported heterogeneity of HRM in small firms (Cassell et al. 2002; Heneman et al. 2000). Finally, 
a methodological contribution is that we involve both owner-managers of small firms and their employees in our study (i.e. a multi-actor approach). Owner-managers provide information on their own entrepreneurial orientation, their HR vision and their HPWP awareness, while employees rate the presence of HPWPs in the firm.

The outline of the remainder of the paper is as follows. First, we outline HPWP theory and introduce the AMO model as the underlying structure (Sect. 2). Next, we introduce the research hypotheses based on the resource-poverty and strategic decision-making perspectives, followed by the research method adopted (Sect. 3). This is followed by the Results section (Sect. 4) and our discussion of the findings (Sect. 5).

\section{Literature review}

In this section, we provide an overview of HPWP theory to demonstrate how the AMO model that underlies HPWPs can be used to discern three smaller but coherent bundles of HR practices. This overview is followed by a literature review based on (1) the resource-poverty perspective and (2) strategic choice models, which results in the generation of the hypotheses.

\subsection{HPWPs and the AMO model}

An HPWP system is conceptualised as the thorough application of only the best practices for HRM (Chadwick 2010), with the latter considered to be individual HRM practices that have been extensively researched and shown to contribute to the enhancement of employee performance. For example, the use of restrictive selection procedures helps to create a workforce of above-average employees who subsequently deliver a better-than-average work performance. Other well-researched best practices are selfmanaged teams, continuing education, employee involvement in organisational strategy, team performance-based pay and paying high salaries.

Further, a combination of best practices impacts on employee and organisational performance beyond the sum of the individual effects of each practice (Boxall and Purcell 2008; Boxall and Macky 2009). That is, there is a bundling or synergy effect (Macduffie 1995;
Combs et al. 2006). For example, introducing selfmanaged work teams without proper training and without the support of team incentives would reduce the increase in employee performance that would normally be expected from teamwork (Macduffie 1995).

Indeed, systematic approaches have been found to have a greater influence than individual practices (Combs et al. 2006). However, a closer inspection of the HPWP research carried out over the past decade reveals several problems. First, not as many organisations have adopted HPWP systems as might be expected given the claimed advantages (Kauhanen 2009). This seems to be especially the case with small organisations (Sels et al. 2006). Second, the practices said to constitute a HPWPs vary from one research project to another, leading to the observation that as few as four practices seem to be consistently part of the HPWP 'system' measured by researchers (Boselie et al. 2005; Boxall and Macky 2009): (1) training and development, (2) contingent pay and reward schemes, (3) performance management (including appraisal) and (4) careful recruitment and selection. This poses the question as to what the 'celebrated' HPWP bundle actually is. Further, the argued-for synergies between all of the best practices in a 'system' are not always found, placing a question mark over the evidence for synergy effects in HPWP systems (Gerhart 2007). In reality, synergies take many forms, and the theoretical foundation for the synergies is as yet not well explored (Chadwick 2010).

A better understanding of synergy effects within bundles of HR practices can be derived from a closer inspection of the drivers of synergy. A theoretical foundation for this synergy occurring is the AMO model (Boxall and Purcell 2008). Here, AMO is an acronym for the three elements that together build sustainable employee performance: individual ability (A), motivation (M) and the opportunity to perform (O). Each of these elements is firmly grounded in industrial/organisational (I/O) psychology, work psychology and human capital theory.

The 'A' component refers to the individual's ability to perform. Individual abilities strongly predict individual job performance (Schmidt and Hunter 1998). Theoretically, the ability component is rooted in the psychology and the economic human capital literature (Gerhart 2007). Practices that contribute to employee ability include the use of advanced employee selection 
techniques and the provision of formal job- and skillrelated training or opportunities to develop skills at work (Appelbaum et al. 2000).

The 'M' deals with motivation: an employee's desire to perform. The theoretical foundation of this component is grounded in social exchange theory (Blau 1964), according to which employee efforts are a reciprocal reaction to their evaluations of the adequacy of incentives, such as pay and promotion opportunities, provided by the organisation. High performance practices linked to motivation are high pay, career opportunities and sharing of information on the company's goals and results (Appelbaum et al. 2000).

The ' $\mathrm{A}$ ' and ' $\mathrm{M}$ ' components have long been central to individual-level theories concerning job performance (Gerhart 2007; Vroom 1964). The additional feature of the AMO model is that it takes account of the work environment in which individuals use their abilities and motivation. As such, the ' $\mathrm{O}$ ' component of AMO refers to the opportunity to perform. Its theoretical foundation lies in job design theories (Hackman and Oldham 1980) and in the employee empowerment literature (Gerhart 2007). Employees who are given autonomy to take workrelated decisions, who work together and share feedback about substantial work goals and who have the opportunity to influence business results experience greater ownership of their work (Spreitzer 1996). Practices that contribute to the opportunity to perform are work meetings, employee involvement in policymaking, work autonomy and teamwork (Appelbaum et al. 2000).

Together, the AMO components stimulate individual employee performance (Appelbaum et al. 2000). At the organisational level, HPWPs form a managerial system aimed at enhancing workforce organisation, workforce capabilities and workforce attitudes that together contribute to organisational performance outcomes (Boxall and Purcell 2008). Reflecting the diverse theoretical backgrounds that contributed to the development of the AMO model of HPWPs, the HPWPs relate to various types of performance (Boxall and Macky 2009). As such, it is possible to introduce employment practices such as training, pay and offering career possibilities (A, M) without changing the work system (O) (Boxall and Macky 2009).

Indeed, Toh et al. (2008) found variations among organisations in their uptake of different sets of practices from the HPWP system. The uptake varied from organisations that had installed none of the HPWP practices ('cost minimisers') to organisations that used only ability-enhancing practices, such as training and restrictive selection ('resource makers'), or only motivation-enhancing practices, such as pay and other incentives ('resource buyers'), to organisations that opted for all the HPWP practices ('commitment maximisers'). Gibson et al. (2007) compared the differential effects of various practices on different types of performance and similarly found that not all practices contribute to the same goals.

To conclude, the literature overview presented above provides mixed support for the single-system approach to HPWPS. The synergy effects of combining HR practices only occur when the practices serve a common goal. By combining the theoretical work of Boxall and Macky (2009) with the empirical findings of Toh et al. (2008), we conclude that each element of the AMO model bundle serves a distinct goal: high employee performance (A), high employee commitment (M) or high workforce empowerment (O). Although these different performance types can be combined in an overall performance-boosting system, this will not necessarily fit with the needs and circumstances of a specific firm and, in particular, not with the needs and circumstances of small firms.

\subsection{Resource-poverty perspective}

The first theoretical perspective holds that the availability of means will influence the implementation of the HR practices. According to the resource-poverty perspective (Welsh and White 1981), means are constrained by the limited availability of financial resources and time, both of which are available in larger quantities in firms with more employees. Related to the resource-poverty perspective, explanations for the low score of small firms on the number of HPWPs present as compared to large organisations have been sought in the costs associated with HPWPs (Sels et al. 2006) and with the concept of informality (Mayson and Barrett 2006).

The explanation based on costs seems straightforward: the size of small firms places constraints on the availability of financial means and the time available to implement advanced HPWPs (Welsh and White 1981). Furthermore, the concept of informality derives from the simple structure of small firms, which 
reduces the need for complex employment management systems (Jack et al. 2006). Larger firms have more complex organisational structures than smaller firms and require more sophisticated ways to align employee behaviour with the goals of the firm (Mintzberg 1979). In the smallest firms, close and interpersonal interactions between employees and direct control by the owners reduce or remove the need for formalised control mechanisms (Davila 2005; De Grip and Sieben 2009). In larger organisations, the complexity of aligning people to organisational goals increases as there is a greater task differentiation between employees which requires more management (Lawrence and Lorsch 1967; Mintzberg 1979). Formalised systems of HR practices reduce the need for direct control and interpersonal interactions (Mintzberg 1979), but these more formal systems for HRM only produce a return when a sufficient number of employees are involved: the returns for smaller firms do not outweigh the time and resources needed to implement HPWPs (Sels et al. 2006).

Davila (2005) found that the largest differences in formalised HR practices were seen in organisations in which the number of employees ranged from one to 30 and in those with more than 75 employees. Few differences in formalisation were observed among firms employing between 30 and 75 employees. This finding underlines the fact that even within a population of micro- and small organisations, the focus of this paper, which is the adoption and elaboration of formal HR practices, does tend to be related to organisation size.

Taken together, these factors suggest that the greater complexity that is characteristic of larger organisations hinders the application of direct control through less resource-intensive informal practice. In combination with the availability of more means, this will lead to the implementation of more formalised HR practices, such as HPWPs, in larger organisations. In terms of the AMO elements of HPWPs, the largest required investments will be in practices related to boosting ability and motivation, since these involve training expenses and high levels of pay. Career opportunities in larger organisations are also more likely to become formalised as roles become more differentiated (Davila 2005). Practices related to opportunity creation are less size dependent because these involve lower costs and can take place in organisations even when jobs are not clearly differentiated (Drummond and Stone 2007). Based on this argument, our first hypothesis is that:

Hypothesis 1 Employees in smaller organisations will perceive fewer motivation and ability practices on average than those in larger organisations.

\subsection{Strategic decision-making}

Although resources needed to implement the more expensive bundles of HPWPs are restricted by firm size, size by itself is insufficient to explain the existence of the different configurations of HPWPs in comparable firms (Lacoursière et al. 2008). As our second theoretical perspective, we focus on the strategic choice of the entrepreneur. In small firms, it is primarily the entrepreneur who is responsible for most of the decisions relating to HRM. In fact, the HR function is often the last position to be delegated to a functional manager (Matlay 1999). Consequently, strategic choices about HPWPs are directly affected by an entrepreneur's knowledge and attitudes. Strategic choice refers to the process whereby the entrepreneur decides upon a specific course of action that is to be taken by the firm in response to the (competitive) environment, the available resources and the design of the structure, rules and routines of the organisation (Child 1997; Edwards et al. 2006). Indeed, when asked, small firm entrepreneurs commonly indicate that they critically evaluate the introduction and use of HR practices against the situation and needs of their firm (Drummond and Stone 2007). Together, these arguments illustrate that the decision of whether or not to implement HPWPs is as much a strategic choice as it is a result of resource constraints.

In short, the decision-making process leading to the implementation of HPWPs seems to be based on two elements: first, an evaluation of the issue at hand as an HR-related issue and, second, the evaluation of the resources needed to deal with the issue by implementing HPWPs (de Kok and Uhlaner 2001).

The first element includes the diagnosis by the firm's management of an organisational problem as an issue worthy of an HR intervention (Cassell et al. 2002). Although the causes underlying company problems are numerous, including competition, company relations and new employment regulations (Mayson and Barrett 2006), not all solutions to such problems necessarily point to the need for an HR 
intervention. The diagnosis as to whether the solution to a given problem involves an HR element, such as the implementation of new set of HR practices, depends on the expertise and attitude of the firm's management. Owner-managers are often reluctant to delegate HR responsibilities (Marlow 2002). Hence, the attitudes and knowledge of the entrepreneur will intervene in the translation of a particular need or problem into an HR intervention (Drummond and Stone 2007; Harney and Dundon 2006). According to upper echelon theory, the characteristics of key decision-makers interfere with rational decision-making (Hambrick and Mason 1984). As such, the effects of individual differences will tend to be magnified especially in small firms, where the owner-manager is the key decision-maker and often enjoys considerable freedom of action (Staw 1991). In particular, the owner's level of knowledge about the beneficial effects of HPWPs (best-practice awareness) is a clear example of restricted expertise that may hamper the performance of small firms (Welsh and White 1981). However, the passion that owner-managers have for various activities in their firm also impacts on their HR-related decisions (Cardon et al. 2009). In this context, their strategic ambition (entrepreneurial orientation) and their general attitude towards people management (HR vision) are particularly important.

The second element directs attention to the fact that when the entrepreneur is in favour of an HR-related intervention, an evaluation of the available resources for implementing the HR intervention then becomes important (Cassell et al. 2002). Here too, the expertise and attitudinal forces that influence strategic decisionmaking with respect to HPWPs will similarly colour the evaluation of the financial resources and time constraints involved in the implementation of HPWPs (Cassell et al. 2002). In some cases, this strategic choice may even counter the straightforward expectation that only available resources (determined by firm size) will determine the uptake of certain HPWPs elements.

In the next section, hypotheses are developed for the second argument, which is the concept that small firm entrepreneurs adopt bundles of HPWPs depending on attitudinal and knowledge-related processes that intervene in the diagnosis and in the resources evaluation made by the entrepreneur as to whether a firm problem justifies the (partial) implementation of HPWPs. Depending on the entrepreneurial orientation, HR vision and bestpractice awareness of the entrepreneur, this may lead to the uptake of different HPWP bundles.

\subsubsection{Entrepreneurial orientation}

Entrepreneurial orientation refers to the strategic orientation of the firm. In small firms, the entrepreneur is the person who drives this orientation. An entrepreneurial orientation is reflected in the initiatives related to the firm's innovativeness, proactiveness and risk taking; for example by trying out new products and services or being more proactive than competitors towards new market opportunities (Covin et al. 1990). Small business owners who demonstrate an entrepreneurial orientation look to implement growth-oriented activities (Kim and Mauborgne 1997).

HRM initiatives need to be viewed from the owner's desire to lead the firm forward by achieving financial results and company growth. While entrepreneurs are characterised by a strong drive and high motivation, their success also depends on their ability to create a strong core team comprising motivated, capable and market-oriented individuals-entrepreneurs expect nothing less from the people they work with (Kuratko 2007). This means a strong emphasis on employees who are as able as the entrepreneur to take the firm forward. In terms of the AMO elements, the emphasis will be on selecting and developing a team that shares the ambitions of the entrepreneur. Hence, practices related to ability are likely to be used in firms led by entrepreneurial owner-managers; it is less likely that these entrepreneurs will adopt motivation and opportunity practices. An owner with an entrepreneurial orientation evokes in employees a sense of being part of a 'winning team' (De Clercq and Rius 2007). The entrepreneurial orientation of the ownermanager energises motivation as a substitute for formal HPWP systems (Liu et al. 2003). In addition, motivation practices are relatively expensive, and their contribution to the entrepreneurial strategy of the firm could be judged as marginal since, as a result of a highly entrepreneurial orientation, employees are already motivated and there is no need for further motivation development. Lastly, opportunity practices involve delegating responsibilities, which would seem to conflict with the preferences of an entrepreneur to keep a tight rein and lead the firm to success. 
Barringer et al. (2005) compared growth-oriented and non-growth-oriented firms and found that growthoriented firms indeed invested more in training, development and incentive schemes. It was apparent that rapid-growth firms depend heavily on the abilities and efforts of their employees to maintain their growth-oriented strategies. This leads to our second hypothesis:

Hypothesis 2 In firms where the owners have a greater entrepreneurial orientation, employees will perceive more practices related to boosting employee ability.

\subsubsection{Best-practice awareness}

One reason why many organisations do not adopt HPWPs is that managers may not be aware of-or actually disagree with-academic research findings on HR 'best practices' (Colbert et al. 2005). Particularly in small firms that do not employ a HR professional, the uptake of best practices is dependent on the ownermanager's insights into this professional field. The awareness of best practices depends on the information channels used by the owner and personal experiences with employee management (Colbert et al. 2005). In most of the literature, the educational level of the owner-manager serves as a proxy for entrepreneurial skills and abilities, including employment management skills (Barringer et al. 2005), but their understanding of HRM can be investigated directly as well (Colbert et al. 2005). More knowledgeable small business managers tend to invest more proactively in HR management (Lacoursière et al. 2008), and when owners are more knowledgeable about best practices, investments in HPWPs are more likely.

We argue here that the effect of best-practice awareness will probably be most apparent in those cases where employee empowerment and involvement are concerned (as in the Opportunity bundle of HPWPs). Although most small firm owners do value a family climate (where friendly and familial relationships with employees are central), strategic decisionmaking usually remains firmly in the hands of the business owner (Marlow 2002). It requires an awareness of the value of involving employees to take the step of delegating responsibilities (Spreitzer and Mishra 1999).

In terms of the interaction of organisation size and best-practice awareness, we reason that the previous logic becomes even more apparent in somewhat larger small organisations. After all, the need to delegate becomes more pressing when more employees need to be managed. However, in a population of micro- and small organisations (up to 50 employees), the ownermanagers of the somewhat larger firms still have the choice to delegate or to keep control firmly in their own hands (Marlow 2002). The decision to delegate and empower employees will be made more quickly by entrepreneurs who have a better understanding of the added value of best practices. Supportive findings for this reasoning were reported by Drummond and Stone (2007) who found that in a population of best small firm employers, owner-managers stated that they had a strong belief in the advantages of involving employees in teamwork, in developing the firm strategy, in daily managerial routines and in designing their own work. These arguments lead to our third pair of hypotheses:

Hypothesis 3A In firms where owners are more aware of best practices, employees will perceive a greater presence of opportunity practices.

Hypothesis 3B In larger small firms, the relationship between the owners' best-practice awareness and opportunity practices will be stronger.

\subsubsection{Innovative HR vision}

Some small firms are quicker than others to adopt modern HR practices (Bacon et al. 1996; Harney and Dundon 2006). The decision to implement modern practices, such as an entire HPWP system, is driven to a certain extent by normative considerations relating to beliefs surrounding the practices (Paauwe and Boselie 2005). Cardon et al. (2009) state that entrepreneurs can be passionate about various activities needed to manage their firms. A passion for people management is evidenced in a desire to be in the vanguard in adopting the newest people management strategies. Various adopter categories for innovative HR are discerned: leaders, fast followers, slow followers and laggards (Paauwe and Boselie 2005). Leaders and fast followers are relatively early in introducing new knowledge or technology to their organisations. They take greater risks than slow followers and laggards, but will benefit the most from competitive advantages if an adopted practice turns out to be beneficial for employee performance. 
The attitude of the entrepreneur towards novel HR practices determines the speed at which these practices will be implemented (Mirvis 1997). Drummond and Stone (2007) found that really successful small firm entrepreneurs not only copied existing practices but also developed innovative HR practices that supported their business philosophy - and that this would lead to HR systems similar to complete HPWP systems, including practices related to increasing ability, motivation and opportunity.

This strategic evaluation of available resources will be most apparent in smaller firms whose owners have a more innovative HR vision. When an owner-manager's desire to be ahead in terms of implementing novel HR practice goes together with more limited resources, as is the case in somewhat smaller firms, these owners will be keener to employ the available resources in favour of the implementation of all three HPWP bundles (Paauwe and Boselie 2005). Just in such a situation [where resources (time and money) are restrained], an owner-manager's vision to be ahead when it comes to implementing novel HR practices is crucial when taking the decision to implement all three HPWP bundles. This leads to the following hypotheses:

Hypothesis 4A In firms where owners pursue a more innovative form of $\mathrm{HR}$, employees will perceive more practices related to all elements of HPWPs: ability, motivation and opportunity.

Hypothesis 4B The relationship between innovative HR and all elements of HPWPs will be stronger in smaller firms than in larger firms.

\section{Method}

\subsection{Procedure and sample}

According to EU guidelines, an organisation is categorised as small when it has fewer than 50 employees and its annual turnover is less than $€ 10$ million (European Commission 2005). Using these criteria, 48 organisations in a Dutch local industry network were approached, of which 45 agreed to participate, which is a $94 \%$ response rate. About half of the organisations operated in the service sector (for example, as financial advisors, an advertising agency or a printing office); the others were in the construction industry (for example, in building, plumbing, stage building). The organisations employed an average of 26 people [standard deviation (SD) 14.80; range 6-52].

Data were obtained using questionnaires to test our hypotheses. Most HRM studies use HR managers as respondents but, given concerns related to single-rater bias (Gerhart et al. 2000) and the reality that in small organisations the entrepreneur has an important role in shaping HRM (Cassell et al. 2002), it was considered important to test the hypotheses with data from both entrepreneurs and employees of independent small organisations. For these reasons, two questionnaires were developed: one for the entrepreneurs and one for their employees. Entrepreneurs were asked to provide information about best-practice awareness, innovative HR and entrepreneurial orientation and about the sector, the age and the size of the organisation. Once the consent of the entrepreneur of an identified company had been secured, the questionnaires for the entrepreneurs were distributed by mail with intensive telephone follow-up. In the covering letter to this survey, the entrepreneur was asked to distribute the employee questionnaire to five employees who were representative of the organisation, who were then asked to provide data on perceived HPWPs.

In total, survey data from 211 employees, all working in the 45 small organisations whose entrepreneurs had agreed to participate, were collected. About $82 \%$ of the entrepreneurs were male, and their average age was 44 (SD 8.37) years. The majority of the entrepreneurs had at least a bachelor's degree. The employees had an average age of 38 (SD 10.50) years and were predominantly male $(64 \%)$. In terms of education, $39 \%$ of the employees had at least a bachelor's degree.

\subsection{Measures}

\subsubsection{Entrepreneurial orientation}

The nine items in Covin and Slevin (1989) entrepreneurial orientation scale were re-worded to make them more appropriate for the entrepreneurial context of our study (see Appendix Table 5 for the re-worded items). Given that we were interested in the orientation of the entrepreneur, we asked the extent to which the various statements applied to their way of managing the organisation. This scale contains items on innovation, 
proactiveness and risk-taking. In line with Lumpkin and Dess (2001) and Stam and Elfring (2008), we replaced the original Covin and Slevin (1989) question that asked whether an organisation prefers to 'undo competitors' or to 'live and let live', with an item asking whether the organisation 'has a strong tendency to follow the leader' or to 'be ahead of other competitors' in introducing new products and services, as a way of measuring proactiveness rather than competitive aggressiveness. All of the items were composed of pairs of opposing statements, with a seven-point response scale between these two extremes. The Cronbach's alpha for this nine-item scale was 0.84 .

\subsubsection{Best-practice awareness}

Best-practice awareness was measured by calculating a knowledge ratio. The degree to which entrepreneurs agreed with HR research findings was assessed using 12 true/false questions designed to be either consistent or inconsistent with research findings on various HRM activities (management, staffing, participation in decision-making, performance appraisal, teamwork, compensation) (Rynes et al. 2002). We selected these 12 (of 35 available) statements because these were the most applicable to the research context (small entrepreneurial organisations in the Netherlands) and because we expected owners to have various levels of knowledge about them (see Appendix Table 6). Reflecting the research setting, one item was reworded. We replaced the original item stating that: 'In order to be evaluated favourably by line managers, the most important competency of HR managers is the ability to manage change' to 'The most important competency of entrepreneurs is the ability to manage change'. A knowledge ratio was computed for each entrepreneur (correct answers divided by 12). The original statements were translated from English into Dutch. The Dutch version was back-translated to English by a native speaker; differences were discussed and adjustments made where necessary.

\subsubsection{Innovative $H R$}

To measure the degree of innovation in the organisation's HR strategy, we used two items drawn from Colbert et al. (2005), which were based on Miles and Snow's (1978) strategic typology. The first item reflects an analyser approach: 'We adopt new human resource practices shortly after they have been tried by other companies'. The second item reflects a prospector approach: 'We are often the first to adopt new or innovative HR practices'. Entrepreneurs were asked to rate their HR strategy on a five-point scale ( $1=$ 'strongly disagree' to $5=$ 'strongly agree') with these two statements. In line with a continuumof-types interpretation (Doty et al. 1993), responses to the two items were averaged to reflect the degree of innovation and proactiveness in an organisation's HR strategy.

\subsubsection{Organisation size}

As an indicator of organisational size, we used the number of employees in the organisation.

\subsubsection{Bundles of HPWPS}

High performance work practices were measured in the employee questionnaire [see Takeuchi et al. (2009) for a similar approach]. A list of HR practices covering the three broad areas or 'bundles' (ability, motivation and opportunity) was developed based on Appelbaum et al. (2000) and on their appropriateness in a Dutch context (see Appendix Table 7).

Five items were included to measure HPWPs that focused on employees' abilities. The first item reflected the willingness of their organisation to develop their employees (Boselie 2002), three items focused on the amount of internal and external training offered by the organisation (Den Hartog and Verburg 2004; Boselie 2002) and the final item concerned the willingness of the organisation to develop employee skills. The resulting Cronbach's alpha for this scale was 0.80 .

Our measure of HPWPs related to employee motivation included six items. Two items focussed on rewards in order to measure the extent to which the organisation paid above-average salaries and the existence of benefits over and above wages (Den Hartog and Verburg 2004), one item was included that measured the presence of career plans for employees (Den Hartog and Verburg 2004) and, as a final indicator, three items focussed on the extent of information sharing within the company (Den Hartog and Verburg 2004). The scale showed good reliability (Cronbach's alpha 0.72). 
A further five items reflected those HPWPs that focus on providing employees with opportunities to perform (Boselie 2002). The first two items concerned autonomy in on-the-job decision-making and focused on the amount of autonomy in work planning and in investing in new materials and technology. The next two items provided indications of the extent of participation in work meetings and in policy-making. A final item addressed teamwork. Cronbach's alpha for this scale was 0.67 .

A confirmatory factor analysis revealed that the hypothesised three-factor model (ability, motivation and opportunity) fit the data significantly better than a one-factor model in which all items were loaded onto a single factor $\left[\Delta \chi^{2}(3)=78.74 ; p<0.05\right]$. These results support the classification of HPWPS into ability-, motivation- and opportunity-focussed practices.

The possible answer categories focussed on how many employees were covered by a specific HPWP, rather than posing the simple question of whether a practice was present or not (Boselie 2002; Gibson et al. 2007), but they did not distinguish between different employee groups. The answer options were: 'this applies to none of the employees', 'this applies to only a few employees', 'this applies to half of the employees', 'this applies to most of the employees' or 'this applies to all employees'.

A higher mean score on these scales indicates a greater perceived presence or intensity of HPWPS practices focussing on ability, motivation or opportunity in the organisation. However, a high score for intensity at the organisational level can result from the application of practices for most employees, or the application of some practices for all employees (Kroon et al. 2009). Given this potential uncertainty, two additional indicators were included. The first additional indicator is 'scope', defined as the number of HPWPs that are applied to at least a few employees; the second is 'depth', which refers to the number of practices that are applied to all employees (Boselie et al. 2005).

To support the aggregation of the individual perceptions of HPWPs into organisation-level scores, we examined certain aggregation statistics: the interrater agreement index $[\operatorname{Rwg}(j)$; James et al. 1984] and two interrater reliability indices (ICC1 and ICC2; Bliese 2000). Provided the $\operatorname{Rwg}(j)$ and ICC2 values are above 0.70 , there is considered to be sufficient justification for aggregation (Klein et al. 2000). The ICC 2 values for the three HRM bundles were 0.84 , 0.82 and 0.80 , respectively, and the corresponding $\operatorname{Rwg}(j)$ values were $0.84,0.83$ and 0.81 . The ICC1 values for the HRM bundles were 0.51 (ability), 0.49 (motivation) and 0.46 (opportunity), indicating in each case that about half of the variance in the HPWPs is attributable to organisational membership. These statistics support the aggregation of the HRM bundles to the organisational level as they suggest that perceptions were widely shared within organisations and also reliably different across organisations (Bliese 2000).

\subsubsection{Control variables}

We controlled for organisation age (the number of years since start-up) and industry (service sector vs. construction industry) in the analyses because these control variables may influence relationships between agency factors, size and HPWPs (Aldrich 1999; Cassell et al. 2002; Chandler and McEvoy 2000).

\subsection{Data analysis}

The analyses for Hypotheses 1-4B involved regression methods. For each HRM bundle (ability, motivation and opportunity), three analyses were performed predicting HRM intensity, depth and scope. We started by testing the effect of owner characteristics and size on the three HRM bundles [Model (M) 1]. Next, we tested the hypothesised interaction between owner characteristics and size on the three HRM bundles (H3 and H4). Here we followed the procedures proposed by Baron and Kenny (1986) and Aiken and West (1991). To compute interaction terms we standardised the predictors, namely, the owner characteristics and the size measure, and then multiplied these standardised values to compute the interaction terms. These interaction terms were then incorporated into the main effect model (M2) (for opportunity practices, interaction effects were modelled separately). Given the relatively small sample size and to gain a clear indication of the relationships involved, we applied a bootstrapping procedure (involving the creation of 2,000 bootstrap samples) using AMOS 6 (Arbuckle 2006) for M1 and M2. The significance of the effects was determined by comparing the probability level $(p)$ from the bootstrapping results (biased 
corrected percentile method) at a significance level of 0.05 (one-tailed significance test). All the analyses were performed at the organisational level of analysis.

\section{Results}

Table 1 shows the means, standard deviations and correlations among the studied variables for the complete sample. As can be seen from Table 1, the mean scores of the three bundles of HPWPs differ. Practices stimulating motivation are less widely implemented than opportunity-creating practices, which are in turn implemented less often than practices that enhance ability. The three elements of HPWPs are moderately correlated with each other (between 0.30 and 0.44). Table 1 further shows that the three approaches to perceiving the bundles of HPWPs (intensity, scope and depth) are moderately to highly correlated $(0.27-0.83)$ with each other. As regards best-practice awareness, the mean score was 0.61 , indicating that the entrepreneurs on average correctly answered $61 \%$ of the HRM knowledge items. Significant correlations were found between entrepreneurial orientation, best-practice awareness, organisation size and the perceived use of ability, motivation and opportunity practices.

Our investigation of the influence of organisation size (Hypothesis 1) revealed a positive effect between organisation size and both ability and motivation practices (but not in terms of depth). The effects were between $0.36^{* *}$ and $0.66^{* *}$, indicating that employees in smaller organisations perceive fewer ability and motivation practices (Tables 2, 3; M1). As such, Hypothesis 1 is largely confirmed.

The next three hypotheses all concerned the influence of owner characteristics on the presence of bundles of HPWPs in the firm. Hypothesis 2 posited a positive relationship between entrepreneurial orientation and the use of ability practices. Table 2 (M1) shows that employees perceive more practices related to ability in firms where the owners have a greater entrepreneurial orientation (scope $\beta=0.18^{*}$ ). Hence, Hypothesis 2 was confirmed.

A second owner characteristic concerned bestpractice awareness (Hypothesis 3). Best-practice awareness was positively related to opportunity practices (in terms of intensity $\beta=0.34 * *$, scope $\beta=0.28 * *$ see Table $4, \mathrm{M} 1$ ), thereby supporting
Hypothesis 3A. The relationship between best-practice awareness and opportunity practices (intensity and depth) was found to strengthen with size ( $\beta=0.26^{*}$ and $\beta=0.40^{* *}$, respectively). To further illustrate the effect of size on the link between bestpractice awareness and opportunity practices, we have shown the significant interactions graphically. Following Aiken and West (1991), simple slopes of the effects of the best-practice awareness on opportunity practices are represented for organisations that are small (one standard deviation below the mean) versus relatively large (one standard deviation above the mean).

Figure 1 illustrates that, in the larger organisations, there is the expected positive association between best-practice awareness and opportunity practices. However, in small organisations the relationship between best-practice awareness and opportunity practices is slightly negative. Finally, we tested the significance of the simple slopes of regression lines at $1 \mathrm{SD}$ above and below the mean of organisation size (Aiken and West 1991). The test confirmed the positive relationship between best-practice awareness and opportunity practices for larger organisations ( $\beta=0.58^{* *}$ and $\beta=0.65^{* *}$, respectively). For small organisations, the negative relationship between bestpractice awareness and opportunity practices was nonsignificant. These results largely confirm Hypothesis 3B.

Further, moderate support was found for Hypothesis 4A, which argued that employees would perceive more of all elements of an HPWP (ability, motivation and opportunity practices) in firms where the owners adopted an innovative HR strategy. Our results show that an innovative HR strategy is positively related to the scope dimension (ability $\beta=0.31^{* *}$, motivation $\beta=0.25^{*}$; opportunity $\beta=0.26^{*}$ ), indicating that employees in firms where the owners have a more innovative HR strategy do perceive ability, motivation and opportunity practices to be more widely applied than their peers in firms where the owner has a less innovative HR strategy. However, the intensity and the depth of HPWPs seemed to be unrelated to an innovative HR strategy.

Finally, only moderate evidence was found to support Hypothesis 4B, i.e. only one significant interaction effect was found. The relationship between innovative HR and motivation scope was stronger in smaller firms than in larger firms $\left(\beta=-0.26^{*}\right)$. 


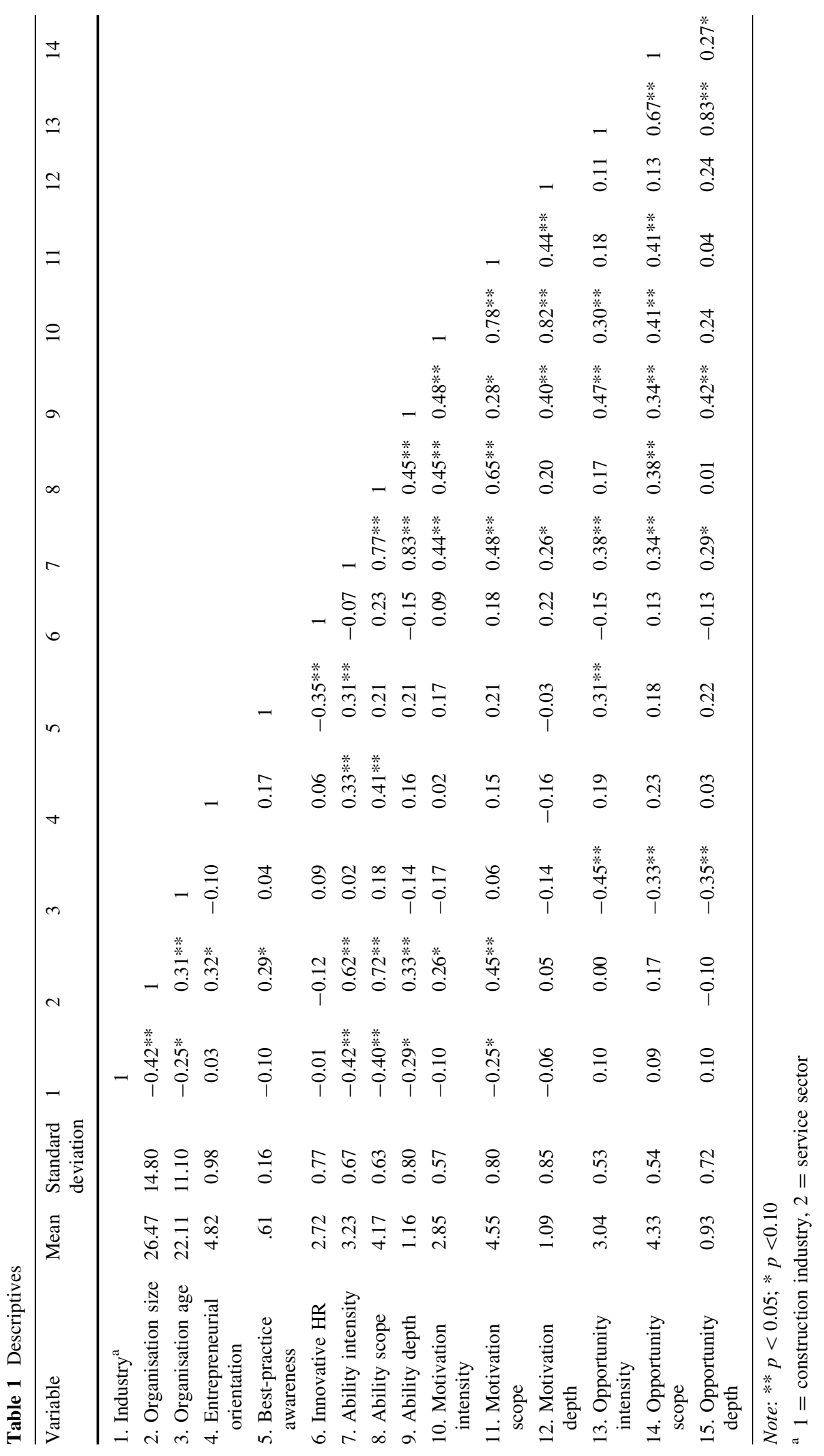


Table 2 Overview of regression models predicting ability

\begin{tabular}{lccr}
\hline Sector & Intensity & Scope & Depth \\
M1 & M1 & -0.14 & -0.24 \\
\hline Industry $^{\mathrm{a}}$ & $-0.25^{*}$ & -0.07 & $-0.27^{*}$ \\
Organisation age & -0.20 & $0.66^{* *}$ & 0.28 \\
Size & $0.53^{* *}$ & $0.18^{*}$ & 0.06 \\
Entrepreneurial orientation & 0.15 & $0.31^{* *}$ & -0.10 \\
Innovative HR & -0.00 & 0.67 & 0.22 \\
$R^{2}$ & 0.48 & & \\
\hline
\end{tabular}

Note: $* * p<0.05, * p<0.10$. Interaction effects between innovative HR and size (M2) were non-significant and not reported here

a $1=$ construction industry, $2=$ service sector

Table 3 Overview of regression models predicting motivation

\begin{tabular}{lcccc}
\hline Sector & Intensity & Scope & Depth \\
\cline { 3 - 5 } & M1 & M1 & M2 & -0.12 \\
\hline Industry $^{\mathrm{a}}$ & -0.02 & -0.08 & -0.12 & -0.06 \\
Organisation age $_{\text {Size }}$ & $-0.30^{*}$ & -0.13 & $0.52^{* *}$ & 0.12 \\
Innovative HR & $0.36^{* *}$ & $0.49^{* *}$ & $0.30^{* *}$ & 0.25 \\
Innovative HR $\times$ size & 0.16 & $0.25^{*}$ & $-0.26^{*}$ & 0.34 \\
$R^{2}$ & 0.16 & 0.28 & 0.10 \\
\hline
\end{tabular}

Note: $* * p<0.05, * p<0.10$. Interaction effects between innovative HR and size (M2) were non-significant for intensity and depth and not reported here

a $1=$ construction industry, $2=$ service sector

Table 4 Overview of regression models predicting opportunity

\begin{tabular}{|c|c|c|c|c|c|}
\hline \multirow[t]{2}{*}{ Sector } & \multicolumn{2}{|l|}{ Intensity } & \multirow{2}{*}{$\begin{array}{l}\text { Scope } \\
\text { M1 }\end{array}$} & \multicolumn{2}{|l|}{ Depth } \\
\hline & M1 & M2 & & M1 & M2 \\
\hline Industry $^{\mathrm{a}}$ & 0.02 & 0.03 & 0.03 & 0.04 & -0.02 \\
\hline Organisation age & $-0.46^{* *}$ & $-0.47 * *$ & $-0.36^{* *}$ & $-0.35^{*}$ & $-0.33^{* *}$ \\
\hline Best-practice awareness & $0.34 * *$ & $0.30^{*}$ & $0.28 * *$ & 0.23 & 0.21 \\
\hline Innovative HR & 0.01 & 0.04 & $0.26^{*}$ & -0.02 & 0.01 \\
\hline Size & & 0.05 & & & -0.11 \\
\hline Best-practice awareness $\times$ size & & $0.26^{*}$ & & & $0.40 * *$ \\
\hline$R^{2}$ & 0.31 & 0.38 & 0.20 & 0.18 & 0.34 \\
\hline
\end{tabular}

Note: $* * p<0.05, * p<0.10$. Interaction effects between innovative HR and size (M2) were non-significant and not reported here. Interaction effect between best-practice awareness and size (M2) was non-significant for scope and not reported here

a $1=$ construction industry, $2=$ service sector

Following Aiken and West (1991) Fig. 2 illustrates that the relationship between innovative HR and motivation scope is positive in small organisations. In comparison, in larger organisations, the relationship between innovative HR and motivation scope is only slightly positive. We tested the significance of the simple slopes of regression lines at $1 \mathrm{SD}$ above and below the mean of organisation size (Aiken and West 1991). The test confirmed the positive relationship between innovative $\mathrm{HR}$ and motivation scope for 

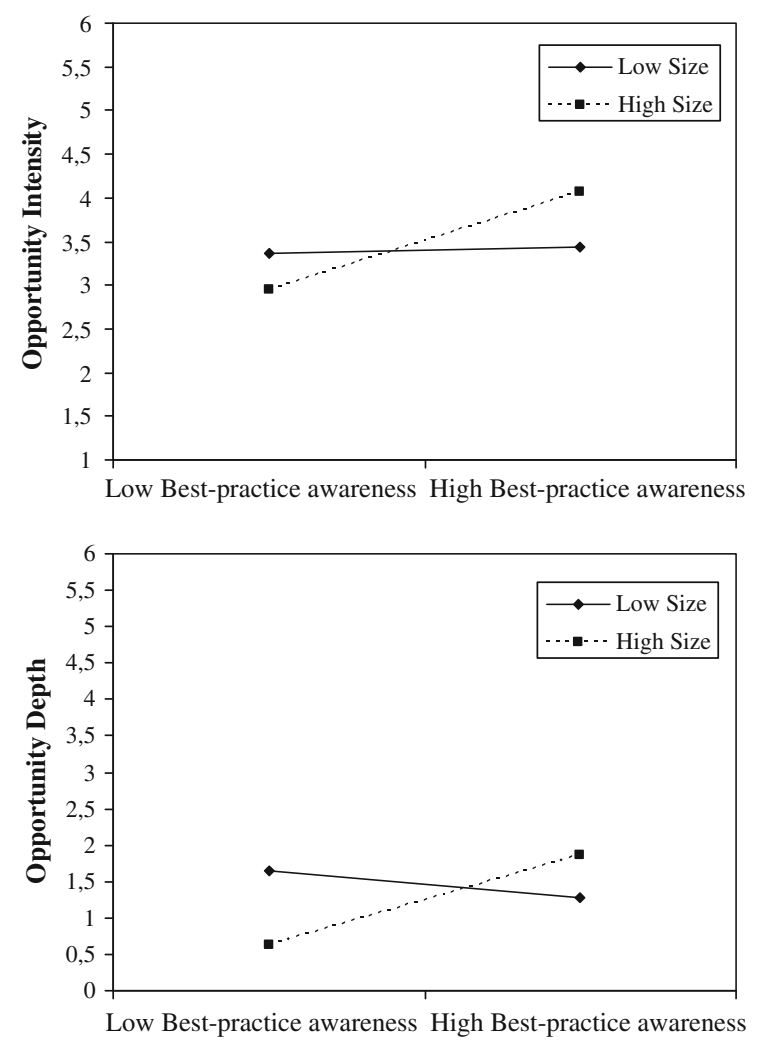

Fig. 1 The association between best-practice awareness and opportunity practices moderated by size

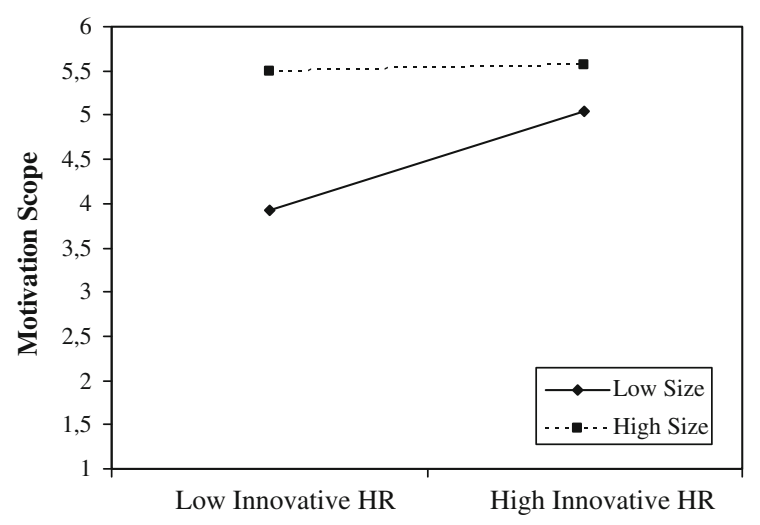

Fig. 2 The association between innovative HR and motivation practices moderated by size

smaller organisations $\left(\beta=0.59^{* *}\right)$; for larger organisations the relationship between innovative HR and motivation scope was non-significant. These results partially confirm Hypothesis 4B (for the scope of motivation practices).

\section{Discussion}

Research into HRM and performance in small firms has embraced the search for HPWPs without really considering the suitability of this model in the context of small firms. In order to advance the discussion on the presence of HPWPs in small firms, we have looked into the probability that small firms adopt smaller sets of related practices instead of the whole package of HPWPs. The AMO model provided a theoretical rationale for the distinction of three smaller bundles of best practices aimed at employee ability (A), motivation $(\mathrm{M})$ and the opportunity to perform $(\mathrm{O})$.

In a study of 45 small organisations (employing between 6 and 52 employees) and a total of 211 employees, we indeed found variation in the presence of the three bundles. This finding emphasises that in studies of best practices, justice is not served by looking only for complete systems of HPWPs and not considering possible alternative strategic applications of best practices. Looking into explanations for this variation, we addressed two complementary perspectives: resource poverty and strategic decision-making.

Resource poverty has to do with constraints in time and money, both of which are typically less available in smaller firms (Welsh and White 1981). In our study, fewer ability and motivation practices were reported by our sample of employees working in the smaller firms (Hypothesis 1). The costs involved in implementing formal training (A), career paths and high salaries (M) can be substantial and particularly difficult to shoulder by smaller firms (Sels et al. 2006). In addition, the greater organisational complexity of larger firms and the increased difficulty in these firms to maintain direct control through an informal approach will lead to the implementation of more formalised ability and motivation practices (Mayson and Barrett 2006). Notably, the scope (i.e. the number of different practices) and the intensity of application (i.e. the proportion of employees covered by these practices) of the ability and motivation bundles were related to organisational size such that, although these practices were present, they did not necessarily apply to all employees.

However, size alone did not explain all of the variation in the AMO bundles in small firms. Notably, our findings illustrate that it is the strategic choice of the owner-manager that also influences which investments in an AMO system are given priority. 
In line with Hypothesis 2, we found that entrepreneurial orientation was related to practices concerning abilities. Small firms that achieve large financial and employee growth are often managed by owners with entrepreneurial orientations. These entrepreneurs are keen resource managers who align all of their resources with organisational growth. As such, for these firms to achieve their goals, it is sufficient to have able employees who can follow the ambitious leader (Kuratko 2007).

A striking finding was that when entrepreneurs had a greater awareness of best practices, their employees reported a larger presence of opportunity practices, thereby supporting Hypothesis 3A. In other words, employees were experienced at being involved in determining the strategy of the firm and deciding on investments, and they also had a say in how to organise their work. The impact of the entrepreneur's bestpractice awareness on employee reports of opportunity practices was especially evident in the somewhat larger organisations; in the smaller organisations, bestpractice awareness did not really influence the level of opportunity practices used (Hypothesis 3B). In our sample of micro- and small organisations, entrepreneurs of the somewhat larger firms could still use autocratic and centralised styles of decision-making (Edwards et al. 2006). One of the most difficult steps for entrepreneurs is to delegate responsibilities to employees (Spreitzer and Mishra 1999). Clearly, knowledge of the beneficial effects of advanced people management practices may help the reluctant entrepreneur to overcome his/her reluctance to empower and involve employees. It would appear entrepreneurs with younger organisations are more open to the use of opportunity practices. The most likely explanation for this finding is that in younger organisations, fewer routines will have crystallised, and more negotiation takes place between owners and employees with the aim of embedding these routines. Maintaining this habit of involving and empowering employees when the firm grows older is a strategic decision related to the entrepreneur's best-practice awareness.

Another finding further illustrates that size alone is not enough to explain the absence or presence of HPWPs. Entrepreneurs who aim to be 'innovative' in their HR strategy can be expected to lead in terms of demonstrating the use of all dimensions of HPWPs. Indeed, employees of such 'innovative' entrepreneurs reported a greater scope associated with each of the three AMO bundles, indicating that these employees perceived that more practices from each of the AMO bundles were present in their firms, although these practices were not necessarily applied to all employees (Hypothesis 4A). In addition, our findings indicate that the relationship between the owner's preference for innovative HR and the scope of motivation practices was most prominent in smaller organisations. This means that in smaller organisations, employees of entrepreneurs with an innovative HR strategy were more likely to report the presence of above-average salaries, financial rewards, formal career plans and company communication. In larger firms, the relationship was less prominent, indicating that it is not merely the greater availability of financial means that facilitates the implementation of motivation practices. This partially confirms Hypothesis 4B. This finding is counter-intuitive, since motivation practices involve pay-related incentives that are considered to be expensive for small firms. Hence, it raises a question about innovativeness in relation to company performance. According to Paauwe and Boselie (2005), a positive attitude towards innovative HR is not necessarily driven by performance considerations; rather, it could be driven by a desire to be the first to try out new things, analogous to the product lifecycle theory's claim of there being innovators, fast followers, slow followers and laggards. This in turn could imply that the more innovative the entrepreneur, the more he/she is willing try out new practices quickly, but without actually intending to develop a performance strategy out of their HRM approach. This would align with the finding that an innovative HR orientation was only related to the scope-and not to the depth-of the actual practices used. Entrepreneurs claiming to be innovative in terms of HR only implement related practices for some employees, rather than working on the basis that providing these practices to all employees would enhance their performance. This raises the question as to whether pursuing modern management practices (such as HPWPs) without reflecting on performance considerations is indeed, as Paauwe and Boselie (2005) put it, 'pursuing best practices in spite of performance'.

Overall, the findings highlight the fact that implementing all the AMO elements of HPWPs can be at odds with the resources of a small firm. In addition, we found that the entrepreneurial orientation, the awareness of best practice and the HR innovativeness 
of owner-managers lead to different preferences when HPWPs are being adopted.

\subsection{Contributions}

The present focus on smaller bundles of strategic combinations of HR practices provides a fruitful and promising approach to investigating HPWPs in small organisations. Hence, the first contribution concerns the investigation of three bundles of HR practices. Much of the theoretical development related to HPWPs has evolved around the AMO model, but without truly considering the diverse performance goals of the practices involved in the bundles (Boxall and Macky 2009). In particular, in small organisations, entrepreneurs have adopted specific HPWP elements and claim to have done so because these fit with the needs of their firms (Drummond and Stone 2007). HPWPs are expensive to implement, and their costs can outweigh the performance benefits (Sels et al. 2006). However, when smaller bundles of practices, aimed at more specific performance goals, are implemented, the associated costs are more modest and the results more closely aligned with the contingent needs of the firm.

The findings presented in this paper illustrate the importance of considering the general notion of resource poverty (given by the size of the organisation) in combination with strategic decision-making models in the framework of HRM investment in small firms.

The study shows that the expertise and attitudes of the owner-manager inform the decision-making processes concerned with the implementation of HPWPs in small firms, over and above restrictions caused by limited financial resources and time constraints (both of which tend to become less problematic with increases in organisation size). Interestingly, the three characteristics of the owner-manager considered (best-practice awareness, entrepreneurial orientation and the desire to have innovative HR practices) were shown to be related to the presence of HPWPs in various ways. As such, the human capital of an ownermanager indeed warrants consideration when researching HRM in small firms. Moreover, the findings indicate that the effect of best-practice awareness and the desire to have innovative HR practices interact with the availability of resources (the size of the small firm). The mechanisms that cause these interactions can be explained by a strategic choice perspective. The felt need to delegate responsibilities to employees $(\mathrm{O})$ does not automatically increase with size, but depends on the awareness of the owner that delegating is a good thing to do. In addition, the drive to be innovative in their HR strategy is of crucial importance for the implementation of motivation practices in smaller firms.

Overall, our research confirms that resource poverty and decision-making factors are both related to the uptake of different HR bundles.

Another contribution involves the measurement of HPWPs. Research into HRM in small firms has struggled with the question of how to measure HR practices. Given the small number of employees, practices are often informal, or they apply to only a few employees (de Kok and Uhlaner 2001). In addressing these measurement issues, we evaluated the presence of the AMO elements in three ways: their intensity, their scope and their depth. An example of the strength of this approach is shown by our finding that the level of innovative HR was only related to the ability, motivation and opportunity bundles, as hypothesised, in terms of scope. Although more practices related to each of the AMO bundles are reported by employees of innovative entrepreneurs, not all employees benefit equally from these practices as they only apply to a few employees. The depth measure of an AMO bundle reflects the number of practices that are applied to all employees. Here we found a negative relationship between the age of the firm and the depth of use of ability practices, indicating that older organisations are more selective in which employees can enjoy ability practices. One possible explanation for this finding is that in the younger organisations the building of the core group of employees is still crucial (Aldrich 1999).

A final contribution concerns the use of multisource data obtained from both owner-managers and employees of small firms in our study (i.e. a multiactor study). This design has enabled us to investigate whether the implementation of HR practices is related to the expertise and knowledge of entrepreneurs while ensuring that common method variance does not bias our results.

\subsection{Limitations}

This research has several limitations. First, the sample was quite small and was focussed on a geographically 
concentrated group of small firms. Due to their geographical proximity, some characteristics of the sample, such as their labour market and employment legislation, can be assumed to have been uniform. However, the advantages of sample homogeneity may come at the cost of being able to generalise the findings. Nevertheless, despite its small size, the sample did provide sufficient variation in both the use of HPWPS and in the hypothesised predictors of high performance work bundles.

Although we used employee perceptions as indicators of the presence of HPWPs in their firms, the sample of respondents was determined by the contact person in the organisation (usually the manager/ entrepreneur). Despite high intra-class correlations which indicate that the averaged perceptions are reliable, it is possible that the samples are not representative of all employees in each organisation. However, the procedure of using multiple respondents in each firm and drawing on multiple actors (employees and entrepreneurs in our study) is advocated as a way of reducing the single respondent bias from which many HR research designs suffer (Gerhart et al. 2000).

Finally, as we took a cross-sectional approach, we cannot be confident of any causal relationships suggested by the results. In order to more confidently understand how HR practices and the availability of resources develop over time, it would be valuable to perform longitudinal case studies.

\subsection{Implications}

Despite claims about the limited uptake and applicability of HRM in small firms, this study contributes to the literature on HRM in small firms by uncovering the presence of aligned bundles of HPWPs in such firms. In addition, this study adds to the literature on resource poverty and strategic decision-making by showing that the implementation of bundles of HPWPs in small firms depends on the size of the organisation, the decision-making by the entrepreneur and the combination of both. In line with a resource-poverty perspective, this study confirms that smaller firms implement fewer ability and motivation practices due to time and financial limitations related to firm scale. However, the influence of the availability of resources needs to be nuanced. This study highlights the fact that the implementation of ability, motivation and opportunity practices is also related to the expertise and outlook of the individual entrepreneur who tends to drive strategic decision-making in small firms. Moreover, this study shows that the expertise and attitudes of these entrepreneurs help to moderate the effect that limited resources have on the uptake of certain elements of HPWPs. More research is needed that integrates the resource-poverty concept and strategic decision-making models to gain greater insight into the conditions under which HPWPs are adopted by small firms.

Open Access This article is distributed under the terms of the Creative Commons Attribution License which permits any use, distribution, and reproduction in any medium, provided the original author(s) and the source are credited.

\section{Appendix}

See Tables 5, 6, and 7.

Table 5 Items measuring entrepreneurial orientation

Left-hand proposition

1. In our organisation, I put a strong emphasis on the marketing of tried and tested products and services

2. I have not introduced new lines of products or services in our organisation

3. During the time I have been head of this organisation the changes in product or services lines have been mostly of a minor nature

4. As an entrepreneur, I typically respond to actions which competitors initiate

5. I am very seldom the first person to introduce new products/ services, administrative techniques and operating techniques within our organisation
Right-hand proposition

In our organisation, I place a strong emphasis on Research and Development, technological leadership and innovation

I have introduced many new lines of products and services

During the time I have been head of this organisation the changes in product or services lines have usually been quite dramatic

As an entrepreneur, I typically initiate actions to which competitors then respond

I am very often the person that introduces new products/ services, administrative techniques and operating techniques within our organisation 
Table 5 continued
Left-hand proposition
Right-hand proposition

6. As an entrepreneur, I have a strong tendency to follow leading competitors

As an entrepreneur, I have a strong tendency to be ahead of other competitors

7. As an entrepreneur, I have a strong proclivity for low-risks projects (with normal and certain rates of return)

As an entrepreneur, I have a strong proclivity for high-risks projects (with possibilities of very high returns)

8. I believe that owing to the nature of the environment, it is best to explore it gradually through timid, incremental behaviour

I believe that owing to the nature of the environment, bold, wide-ranging actions are necessary to achieve the organisation's objectives

9. As an entrepreneur, I typically adopt a cautious, 'wait-and-see' posture in order to minimise the probability of making costly decisions

As an entrepreneur, I typically adopt a bold, aggressive posture in order to maximise the probability of exploiting potential opportunities

Table 6 Items measuring best-practice awareness

1. The most valid employment interviews are designed around each candidate's unique background

2. On average, applicants who answer job advertisements are likely to have higher turnover than those preferred by other employees

3. Being very intelligent is actually a disadvantage for performing well on a low-skilled job

4. On average, encouraging employees to participate in decision-making is more effective for improving organisational performance, than setting performance goals

5. Teams with members from different functional areas are likely to reach better solutions to complex problems than teams from a single area

6. Companies with vision statements perform better than those without them

7. Most managers give employees lower performance appraisals than they objectively deserve

8. Leadership training is ineffective because good leaders are born, not made

9. Most errors in performance appraisals can be eliminated by providing training that describes the kinds of errors management tend to make and suggesting ways to avoid them

10. Most employees prefer to be paid on the basis of individual performance rather than on team or organisational performance

11. When pay must be reduced or frozen, there is little a company can do or say to reduce employee dissatisfaction and dysfunctional behaviours

12. The most important competency of entrepreneurs is the ability to manage change

Table 7 Items measuring perceptions of high performance work practices

\begin{tabular}{ll}
\hline Ability & Our organisation tries to educate its employees \\
Within our organisation it is possible to follow formal internal training courses \\
Our organisation offers the possibility to follow external training courses \\
Employees follow training courses to improve their social skills \\
Our organisation offers the possibility to develop skills \\
Motivation \\
Our company pays above-average salaries \\
Beside their normal wage, employees receive a bonus or another financial reward \\
The organisation has formal career plans for its employees \\
Employees are informed about all future plans of the organisation \\
Employees are informed about the organisation's returns \\
In our organisation, employees are informed about the organisation's vision and mission \\
Within our organisation, employees plan their own work \\
Employees are free to invest in new materials and technology \\
Employees participate in work meetings \\
Employees are involved in policy-making \\
Employees work together in teams
\end{tabular}




\section{References}

Aiken, L. S., \& West, S. G. (1991). Multiple regression: Testing and interpreting interactions. Thousand Oakes, CA: Sage.

Aldrich, H. E. (1999). Organizations evolving. London: Sage.

Appelbaum, E., Bailey, T., Berg, P., \& Kalleberg, A. L. (2000). Manufacturing advantage: Why high-performance work systems pay off. Ithaca: Cornell University Press.

Arbuckle, J. L. (2006). AMOS. Spring House: AMOS Development Cooperation.

Bacon, N., Ackers, P., Storey, J., \& Coates, D. (1996). It's a small world: Managing human resources in small businesses. International Journal of Human Resource Management, 7(1), 82-100. doi:10.1080/09585190500314706.

Baron, R. M., \& Kenny, D. A. (1986). The moderator-mediator variable distinction in social psychological research: Conceptual, strategic and statistical considerations. Journal of Personality and Social Psychology, 51(6), 11731182. doi:10.1037//0022-3514.51.6.1173.

Barringer, B. R., Jones, F. F., \& Neubaum, D. O. (2005). A quantitative content analysis of the characteristics of rapidgrowth firms and their founders. Journal of Business Venturing, 20(5), 663-687. doi:10.1016/j.jbusvent.2004. 03.004 .

Blau, P. M. (1964). Exchange and power in social life. New Brunswick, NJ: Transaction Publishers.

Bliese, P. D. (2000). Within-group agreement, non-independence, and reliability: Implications for data aggregation and analysis. In K. J. Klein \& S. W. J. Kozlowski (Eds.), Multilevel theory, research, and methods in organizations: Foundations, extensions, and new directions (pp. 349381). San Francisco: Jossey-Bass.

Boselie, P. (2002). Human resource management, work systems and performance: A theoretical-empirical approach. Rotterdam: Erasmus University.

Boselie, P., Dietz, G., \& Boon, C. (2005). Commonalities and contradictions in HRM and performance research. Human Resource Management Journal, 15(3), 67-94. doi:17488583.2005.tb00154.x.

Boxall, P., \& Macky, K. (2009). Research and theory on highperformance work systems: Progressing the high-involvement stream. Human Resource Management Journal, 19(1), 3-23. doi:10.1111/j.1748-8583.2008.00082.x.

Boxall, P., \& Purcell, J. (2008). Strategy and human resource management. Basingstoke: Palgrave Macmillan.

Cardon, M. S., Wincent, J., Singh, J., \& Drnovsek, M. (2009). The nature and experience of entrepreneurial passion. Academy of Management Review, 34(3), 511-532. doi: 10.5465\%2FAMR.2009.40633190.

Cassell, C., Nadin, S., Gray, M., \& Clegg, C. (2002). Exploring human resource management practices in small and medium sized enterprises. Personnel Review, 31(5-6), 671692. doi:10.1108/00483480210445962.

Chadwick, C. (2010). Theoretic insights on the nature of performance synergies in human resource systems: Toward greater precision. Human Resource Management Review, 20(2), 85-101. doi:10.1016/j.hrmr.2009.06.001.

Chandler, G. N., \& McEvoy, G. M. (2000). Human resource management, TQM, and firm performance in small and medium sized enterprises. Entrepreneurship: Theory \& Practice, 25, 43-58.

Child, J. (1997). Strategic choice in the analysis of action, structure, organizations and environment: Retrospect and prospect. Organization Studies, 18(1), 43-76. doi:10.1177/ 017084069701800104.

Colbert, A. E., Rynes, S. L., \& Brown, K. G. (2005). Who believes us?: Understanding managers' agreement with human resource research findings. The Journal of Applied Behavioral Science, 41, 304-325. doi:10.1177/0021886 305275799.

Combs, J., Liu, Y. M., Hall, A., \& Ketchen, D. (2006). How much do high-performance work practices matter? A metaanalysis of their effects on organizational performance. Personnel Psychology, 59(3), 501-528. doi:10.1111/j. 1744-6570.2006.00045.x..

Covin, J. G., \& Slevin, D. P. (1989). management of small firms in hostile and benign environments. Strategic Management Journal, 10(1), 75-87. doi:10.1002/smj.4250100107.

Covin, J. G., Slevin, D. P., \& Covin, T. J. (1990). Content and performance of growth-seeking small firms: In high and low technology industries. Journal of Business Venturing, 5(6), 391-412. doi:10.1016/0883-9026(90)90013-j.

Dandridge, T. C. (1979). Children are not 'little grown-ups': Small business needs its own organizational theory. Journal of Small Business Management, 17(2), 53-57.

Davila, T. (2005). An exploratory study on the emergence of management control systems: Formalizing human resources in small growing firms. Accounting, Organizations and Society, 30(3), 223-248. doi:10.1016/j.aos.2004.05.006.

De Clercq, D., \& Rius, I. M. (2007). Organizational commitment in mexican small and medium-sized firms: The role of work status, organizational climate, and entrepreneurial orientation. Journal of Small Business Management, 45(4), 467-490. doi:10.1111/j.1540-627X.2007.00223.x.

De Grip, A., \& Sieben, I. (2009). The effectiveness of more advanced human resource systems in small firms. International Journal of Human Resource Management, 20(9), 1914-1928. doi:10.1080/09585190903142373.

de Kok, J., \& Uhlaner, L. M. (2001). Organization context and human resource management in the small firm. Small Business Economics, 17(4), 273-291. doi:10.1023/a:101 2238224409.

Den Hartog, D. N., \& Verburg, R. M. (2004). High performance work systems, organisational culture and firm effectiveness. Human Resource Management Journal, 14, 55-78. doi:10.1111/j.1748-8583.2004.tb00112.x.

Doty, D. H., Glick, W. H., \& Huber, G. P. (1993). Fit, equifinality, and organizational effectiveness: A test of two configurational theories. Academy of Management Journal, 36(6), 1196-1250. doi:10.2307/256810.

Drummond, I., \& Stone, I. (2007). Exploring the potential of high performance work systems in SMEs. Employee Relations, 29(2), 192-207. doi:10.1108/01425450710 720011.

Edwards, P., Ram, M., Sen Gupta, S., \& Tsai, C. (2006). The structuring of working relationships in small firms: Towards a formal framework. Organization, 13(5), 701-724. doi:10.1177/1350508406067010. 
European Commission. (2005). The new SME definition: User guide and model declaration. Brussels: Publication Office.

Gerhart, B. (2007). Horizontal and vertical fit in human resource systems. In C. Ostroff \& T. A. Judge (Eds.), Perspectives on organizational fit (pp. 317-350). Hillsdale, NJ: Erlbaum.

Gerhart, B., Wright, P. M., McMahan, G. C., \& Snell, S. A. (2000). Measurement error in research on human resources and firm performance: How much error is there and how does it influence effect size estimates? Personnel Psychology, 53(4), 803-834. doi:10.1111/j.1744-6570.2000. tb02418.x.

Gibson, C. B., Porath, C. L., Benson, G. S., \& Lawler, E. E. (2007). What results when firms implement practices: The differential relationship between specific practices, firm financial performance, customer service, and quality. Journal of Applied Psychology, 92(6), 1467-1480. doi: 10.1037/0021-9010.92.6.1467.

Hackman, J. R., \& Oldham, G. R. (1980). Work redesign. Reading, MA: Addison-Wesley.

Hambrick, D. C., \& Mason, P. A. (1984). Upper echelons: The organization as a reflection of its top managers. Academy of Management Review, 9(2), 193-206. doi:10.2307/258434.

Harney, B., \& Dundon, T. (2006). Capturing complexity: Developing an integrated approach to analysing HRM in SMEs. Human Resource Management Journal, 16(1), 48-73. doi:10.1111/j.1748-8583.2006.00004.x.

Heneman, R. L., Tansky, J. W., \& Camp, S. M. (2000). Human resource management practices in small and medium-sized enterprises: Unanswered questions and future research perspectives. Entrepreneurship: Theory \& Practice, 25(1), 11.

Jack, S., Hyman, J., \& Osborne, F. (2006). Small entrepreneurial ventures culture, change and the impact on HRM: A critical review. Human Resource Management Review, 16(4), 456-466. doi:10.1016/j.hrmr.2006.08.003.

James, L., Demaree, R. G., \& Wolf, G. (1984). Estimating within-group interrater reliability with and without response bias. Journal of Applied Psychology, 69(1), 85-98

Kauhanen, A. (2009). The incidence of high-performance work systems: Evidence from a nationally representative employee survey. Economic and Industrial Democracy, 30(3), 454-480. doi:10.1177/0143831x09336560.

Kim, W. C., \& Mauborgne, R. (1997). Value innovation: The strategic logic of high growth. Harvard Business Review, 75(1), 102-112.

Klein, K. J., Bliese, P. D., Kozlowski, S. W. J., Dansereau, F., Gavin, M. B., Griffin, M. A.,Hofmann, D. A., James, L. R., Yammarino, F. J., \& Bligh, M. C. (2000). Multilevel analytical techniques: commonalities, differences, and continuing questions. In K. J. Klein \& S. W. J. Kozlowski (Eds.), Multilevel theory, research and methods in organizations: foundations, extensions, and new directions (pp. 512-553). San Francisco, CA: Jossey-Bass.

Kroon, B., van de Voorde, K., \& van Veldhoven, M. (2009). Cross-level effects of high-performance work practices on burnout: Two counteracting mediating mechanisms compared. Personnel Review, 38(5), 509-525. doi:10.1108/ 00483480910978027.

Kuratko, D. F. (2007). Entrepreneurial leadership in the 21st century. Journal of Leadership \& Organizational Studies, 13(4), 1-11. doi:10.1177/10717919070130040201.
Lacoursière, R., Fabi, B., \& Raymond, L. (2008). Configuring and contextualising HR systems: An empirical study of manufacturing SMEs. Management Revue, 19(1/2), 106-125.

Lawrence, P. R., \& Lorsch, J. W. (1967). Organization and environment: Managing differentiation and integration. Cambridge, MA: Harvard University Press.

Liu, W., Lepak, D. P., Takeuchi, R., \& Sims, H. P., Jr. (2003). Matching leadership styles with employment modes: Strategic human resource management perspective. Human Resource Management Review, 13(1), 127. doi: 10.1016/s1053-4822(02)00102-x.

Lumpkin, G. T., \& Dess, G. G. (2001). Linking two dimensions of entrepreneurial orientation to firm performance: The moderating role of environment and industry life cycle. Journal of Business Venturing, 16(5), 172-429. doi: 10.1016/s0883-9026(00)00048-3.

Macduffie, J. P. (1995). Human resource bundles and manufacturing performance: Organizational logic and flexible production systems in the world auto industry. Industrial and Labor Relations Review, 48(2), 197-221. doi: $10.2307 / 2524483$.

Marlow, S. (2002). Regulating labour management in small firms. Human Resource Management Journal, 12(3), 25-43. doi:10.1111/j.1748-8583.2002.tb00069.x.

Matlay, H. (1999). Employee relations in small firms: A microbusiness perspective. Employee Relations, 21(3), 285-295. doi:10.1108/01425459910273125.

Mayson, S., \& Barrett, R. (2006). The 'science' and 'practice' of HRM in small firms. Human Resource Management Review, 16(4), 447-455. doi:10.1016/j.hrmr.2006.08.002.

Miles, R. E., \& Snow, C. C. (1978). Organization strategy, structure, and process. New York: McGraw-Hill.

Mintzberg, H. (1979). The structuring of organizations. Upper Saddle River, NJ: Prentice Hall.

Mirvis, P. H. (1997). Human resource management: Leaders, laggards, and followers. The Academy of Management Executive, 11(2), 43-56. doi:10.5465\%2FAME.1997.970 7132148.

Paauwe, J., \& Boselie, P. (2005). 'Best practices... in spite of performance': Just a matter of imitation? International Journal of Human Resource Management, 16(6), 987-1003. doi:10.1080/09585190500120798.

Rynes, S. L., Colbert, A. E., \& Brown, K. G. (2002). HR professionals' beliefs about effective human resource practices: Correspondence between research and practice. Human Resource Management, 41(2), 149-174. doi: 10.1002/hrm.10029.

Schmidt, F. L., \& Hunter, J. E. (1998). The validity and utility of selection methods in personnel psychology: Practical and theoretical implications of 85 years of research findings. Psychological Bulletin, 124(2), 262-274. doi:10.1037/ 0033-2909.124.2.262.

Sels, L., De Winne, S., Maes, J., Delmotte, J., Faems, D., \& Forrier, A. (2006). Unravelling the HRM-performance link: Value-creating and cost-increasing effects of small business HRM. Journal of Management Studies, 43(2), 319-342. doi:10.1111/j.1467-6486.2006.00592.x..

Spreitzer, G. M. (1996). Social structural characteristics of psychological empowerment. Academy of Management Journal, 39(2), 483-504. doi:10.2307/256789. 
Spreitzer, G. M., \& Mishra, A. K. (1999). Giving up control without losing control-Trust and its substitutes' effects on managers' involving employees in decision making. Group \& Organization Management, 24(2), 155-187. doi:10. 1177/1059601199242003.

Stam, W., \& Elfring, T. (2008). Entrepreneurial orientation and new venture performance: The moderating role of intraand extraindustry social capital. Academy of Management Journal, 51(1), 97-111. doi:10.5465\%2FAMJ.2008.307 44031.

Staw, B. M. (1991). Dressing up like an organization: When psychological theories can explain organizational action. Journal of Management, 17(4), 805-819. doi:10.1177/014 920639101700412.

Takeuchi, R., Chen, G., \& Lepak, D. P. (2009). Through the looking glass of a social system: Cross-level effects of high-performance work systems on employees' attitudes. Personnel Psychology, 62(1), 1-29. doi:10.1111/j.17446570.2008.01127.x.

Toh, S. M., Morgeson, F. P., \& Campion, M. A. (2008). Human resource configurations: Investigating fit with the organizational context. Journal of Applied Psychology, 93(4), 864-882. doi:10.1037/0021-9010.93.4.864.

Vroom, V. H. (1964). Work and motivation. New York: Wiley.

Way, S. A. (2002). High performance work systems and intermediate indicators of firm performance within the US small business sector. Journal of Management, 28(6), 765-785. doi:10.1016/s0149-2063(02)00191-5.

Welsh, J. A., \& White, J. F. (1981). A small business is not a little big business. Harvard Business Review, 59(4), 18-32. 